Research Article

\title{
Resilience to Food Insecurity among Rural Households in the Punjab, Pakistan
}

\author{
Mahwish Munawar ${ }^{1}$, Xu Shiwei ${ }^{1}$, Yu Wen ${ }^{1}$ and Muhammad Luqman ${ }^{2 *}$ \\ ${ }^{1}$ Agricultural Information Institute of CAAS, Beijing, China; ${ }^{2}$ University of Sargodha, Sargodha, Pakistan.
}

\begin{abstract}
Strategies adopted by a household to deal with natural, economic, and social shocks depend upon available resources and capabilities. Families belonging to different vicinities and socio-economic groups have different earning and utilising earnings to fulfil their basic needs. Households need various interventions for well-being. While keeping in view the situation, this study planned to deepen insight into rural households' food consumption system. Food consumption score and household food insecurity access score index were used for precise estimation of food consumption behaviour and food security level weekly and monthly. Food Consumption Score indicated that households are less food insecure weekly; not a single-family consumes less than required food. But when we analyze rural households' consumption behaviour, up to 50 per cent of the population is on the borderline of food security. Little shock can lead them to food insecurity. Results show that an increase or decrease in income or fluctuation in an economy severely affects food consumption, even at the grass-root level. For upgrading the livelihood patterns and food security situation, a stable economy is an essential factor. Policymakers should modify food security plans according to the ever-changing needs of the population. The national poverty and food insecurity management departments of developing countries should be improved so that vulnerability to food security and food loss can be predicted more accurately.

Received | February 04,2021; Accepted | March 21, 2021; Published | June 19, 2021

*Correspondence | Muhammad Luqman, University of Sargodha, Sargodha, Pakistan; Email: muhammad.luqman@uos.edu.pk

Citation | Munawar, M., X. Shiwei, Y. Wen and M. Luqman. 2021. Resilience to food insecurity among rural households in the Punjab, Pakistan. Sarbad Journal of Agriculture, 37(3): 754-762.

DOI | https://dx.doi.org/10.17582/journal.sja/2021/37.3.754.762

Keywords | Food security, FCS (Food Consumption Score), Household Food Insecurity Access Score (HFIAS), Resilience, Rural Pakistan
\end{abstract}

\section{Introduction}

$\mathrm{F}$ ood insecurity is a stubborn issue in most developing countries around the globe (Habib et al., 2018). Poverty, Deprivation of natural resources, the inadequacy of resources essential for agriculture and unequal distribution of food, etc. are significant causes of food insecurity (Arshad and Shafqat, 2012; Hamelin et al., 2008; Maziya et al., 2017; ODI, 2008; von Grebmer et al., 2014). Pakistan is facing severe issues of food security. A vast majority of the country's rural population is vulnerable to food insecurity, and as a coping strategy, this vulnerable population consume less nutritive food (Anila, 2011; Hussain and Akram,
2008). Conflicts and illiteracy, low purchasing power, social and economic issues are significant obstacles to providing nutritious and balanced food (Farkhanda et al., 2009).

Food security defines access, affordability and availability to nutritious, safe, and sufficient food for a healthy and active lifestyle for all people at all times (FAO, 2012). Household food security is the notion relevant to all levels of the family system. Food is a fundamental essential for mental and physical growth and human beings' daily nourishment (Amaral et al., 2013; Dercon and Krishnan, 1996; Morton et al., 2007). Availability and accessibility 
to food is a fundamental human right (Maxwell, 1996). Individual productivity is critically influenced by malnutrition and under-nourishment at the household and national levels. This problem is more drastic and critical in developing and underdeveloped countries (FAO, 2012).

During the last decades, a new concept related to food security has been proposed, known as resilience to food insecurity (Alinovi et al., 2010). Stability is a correlated but diverse concept from vulnerability. It can be defined as the household's ability to handle risks and coop up with shocks and stress depending upon available options and resources. Both vulnerability and resilience have standard parameters such as the stresses, strains and shocks, which a social-economic system experience, according to its adaptive capacity (Løvendal et al., 2004). Resilience analysis explains how change and disturbances influence a system's structure and how it works to fulfil needs (Dercon and Krishnan, 1996).

Subcontinent (India and Pakistan) is among the most significant agricultural producers globally, and still, every night, more than 500 million individuals go to sleep hungry. South Asia is among the supreme food-insecure regions of the world. For Pakistan, food insecurity is a horrible nightmare (Asghar and Muhammad, 2013). Pakistan ranked $78^{\text {th }}$ in the list of countries facing food insecurity (Economist Intelligence Unit, 2019). According to the Human Development Index (HDI), in 2015, Pakistan retained $147^{\text {th }}$ out of 188 countries, and now, after five years, it ranked $154^{\text {th }}$ out of 189 countries (United Nations Development Programme (UNDP, 2020). The HDI value of Pakistan is 0.547 , which is lesser than Asia's average value (0.622) and the world's average value of 0.683 (United Nations Development Programme (UNDP, 2020). In terms of food security Pakistani population can be divided into four groups food secure, bordered line, food insecure, and last one extremely vulnerable living below the line of poverty (Ahmad et al., 2015).

Pakistan has been facing issue of food insecurity due to several factors like natural disasters (earthquake, floods, etc.), military operations, war and terror, in the suburban. According to the Global Hunger Index (GHI), Pakistan ranked 94 out of 117 countries, indicating how much food insecurity persists, which is exceptionally alarming (Grebmer et al., 2015).
The causes of food security have been the main focus of researchers of different regions like Ethiopia (Bogale, 2012; von Grebmer et al., 2014), Brazil (Coelho et al., 2010; Felker-Kantor and Wood, 2012; Rose, 2008), Zimbabwe (Muhoyi et al., 2014; Nyikahadzoi et al., 2012), Kenya (Kassie et al., 2014; USAID, 2010), Ghana (Owusu et al., 2011), and Nigeria (Arene and Anyaeji, 2010; Oyekale et al., 2017). Some studies for Pakistan are (Asghar and Muhammad, 2013; Mebratu, 2018; Sheikh et al., 2020; Sultana et al., 2009), but they are either for whole Pakistan (Khan et al., 2012) or other provinces, i.e., for Punjab (Bashir et al., 2012c). Some studies also utilized secondary data (Anila, 2011). This research was designed to observe the food security level of households living in the countryside of different districts by calculating varying food security measures.

\section{Materials and Methods}

\section{Theoretical description of parameters and calculation method}

Food Consumption Score (FCS): The Food Consumption Score (FCS) is a method that was established by the World Food Programme (WFP) in 1996 to measure the level of food intake weekly. Food consumption scores were measured based on the rate of food, dietary diversity, and the nutritional significance of the unique nine meal groups. The FCS was invented to transmit the quality and volume of people's diets at the domestic level. A combined score was calculated with a weighted sum based on the type of meal and rate of consumption of different food items for seven days, weighted according to the consumed food groups' relative nutritional value. For example, food groups containing highly nutritious foods, like dairy and meat, are given higher weightiness than those with less nutritional value, such as pulses, tubers, and sugar-containing items. Household's food consumption can be categories into three groups: acceptable, borderline, and low, and The food consumption score is an indicator of domestic caloric intake weekly. Different food intake questions were used to acquire statistics related to typical families' consumption behaviour in Pakistan. The household head had been questioned about the frequency of consumption of different food items during the last seven days. FCS was estimated with the formula proposed in "the emergency food security assessment handbook" (WFP, 2009). In the method, the food consumption score was calculated by multiplying the weight for 
each food group/type with the number of days given food groups were consumed. The formula can be expressed as follows:

$F C S=a 1 \times f($ cereal and or tubers $)+a 2 \times f($ pulse $)+$ $a 3 \times f$ (milk) $+a 4 \times f$ (fruit) $+a 5 \times f$ (meat and or fish) $+a 6 \times f$ (sugar) $+a 7 \times f$ (vegetables) $+a 8 \times f($ oil $)+a 9 \times f$ (condiments)

Explanation of factors: FCS= Food Consumption Score; $f=$ frequency (number of days for which each given food group was consumed during the past week); $\mathrm{a}=$ weighted value representing the nutritional value of selected food groups.

Food groups had been assigned specific weights reflecting their nutritional density. The FCS has three categories of food consumption 1) less food consumption (0-21), 2) marginal food consumption $(21<\mathrm{FCS} \leq 35)$, and 3$)$ up to mark food consumption (FCS > 35) (WFP, 2009). The FCS was adopted because it offers a greater accurate measure of household nourishment. However, the FCS bears some weaknesses because it no longer thinks about foods bump off outside the household. It does not furnish any facts about intra-household meal delivery. To some extent, the seven-day recall makes it impossible to consider the volume of meals eaten. Despite its weaknesses, FCS is nevertheless viewed as one of the prudent measures of household meal security.

\section{Household food insecurity access score (HFLAS)}

The HFIAS is an instrument used to measure food insecurity in the household during the last 30 days. HFIAS reflects the three levels of household food insecurity: depression and anxiety, low quality, and inadequate quantity of food provisions. This index reveals the household's insight about diet intake regardless of its nutritional value (Coates et al., 2007; Mango et al., 2014; Vaitla et al., 2015). This food insecurity index emphasizes consumptionrelated plans and the household's behavioral and psychological responses to food consumption levels. (Deitchleret al., 2011; Coates et al., 2007). During the survey, the respondents were asked nine questions about increasing level of food insecurity. The occurrence questions can be brief as follows:

(Q1a) eating the kinds of less preferred foods; (Q2a) worrying about food adequacy; (Q3a) eating limited variety; (Q4a) inability to eat less favourite foods; (Q5a) eating a smaller meal than needed; (Q6a) eating fewer meals in a day; (Q7a) failing to get food of any kind; (Q8a) sleeping at night hungry; (Q9a) going the whole day or night ( 24 hours) without eating anything.

Respondents were asked to respond in yes $=1$ if the event occurred or no $=0$ if the incident did not happen. Each question is followed by a frequency of happening during the previous month. The minimum score of HFIAS is zero when a household head responds 'no' to all questions. Alternatively, 27 is the maximum score of HFIAS. It is obtained when a family responds yes to all inquiries and 'often' as the frequency of occurrence to all nine items. HFIAS $(0-27)$ at a higher value present that a household is food insecure. Simultaneously, a low score indicates that the family is less vulnerable to food insecurity (Nyikahadzoi et al., 2012). The HFIAS is computed as follows:

\section{$H F I A S(0-27)=Q 1 a^{*} F 1+Q 2 a^{*} F 2+Q 3 a^{*} F 3+Q 4 a-$ ${ }^{*} F 4+Q 5 a^{*} F 5+Q 6 a^{*} F 6+Q 7 a^{*} F 7+Q 8 a^{*} F 8+Q 9 a^{*} F 9$..(2)}

\section{Data collection}

Quantitative Primary as well as secondary data were used in the completion of this research. Available secondary data was collected and organized from both previous and current related studies, found in the library of the University of Agriculture Faisalabad and the Chinese Academy of Agriculture Sciences, NGOs offices, academic and research institutions, journals, books, and the internet sources. The online available reports and information regarding different household food security projects run by international organizations (FAO, IFPRI, WFO) were used. The primary data was gathered from the field by meeting farming household heads. The pre-designed and tested questionnaire was used for data collection. The interviews with household heads and focus group discussions with the whole family were conducted to peep deep inside the household's food consumption system. Information regarding different food security parameters, annual consumption, and price of different food groups were gathered.

\section{Sample/universe size}

A multi-stage sampling technique was used to select study sites, and 166 farming households from five agro-climatic zones were selected. In the first stage, 
Punjab province, which is divided into five different agro-climatic zones (Sultana et al., 2009; Bashir et al., 2012a; Akram and Sial, 2019), was selected (Figure 1). According to the Pakistan Bureau of Statistics, Punjab province consists of 36 districts, out of which five districts were determined using a stratified purposive sampling technique. According to the selection criteria, one community was chosen from each zone. The area was selected due to the uniformity in the production of five major crops (wheat, rice, sugarcane, cotton, and maize) (Aslam, 2016). In the third stage, one village was arbitrarily nominated from each district. In the fourth stage, 40 households from each community were selected haphazardly. This criterion was used to form a sample of 200 families. Due to incomplete and inappropriate information, 34 homes were dropped, and data of 166 households were used to get results.

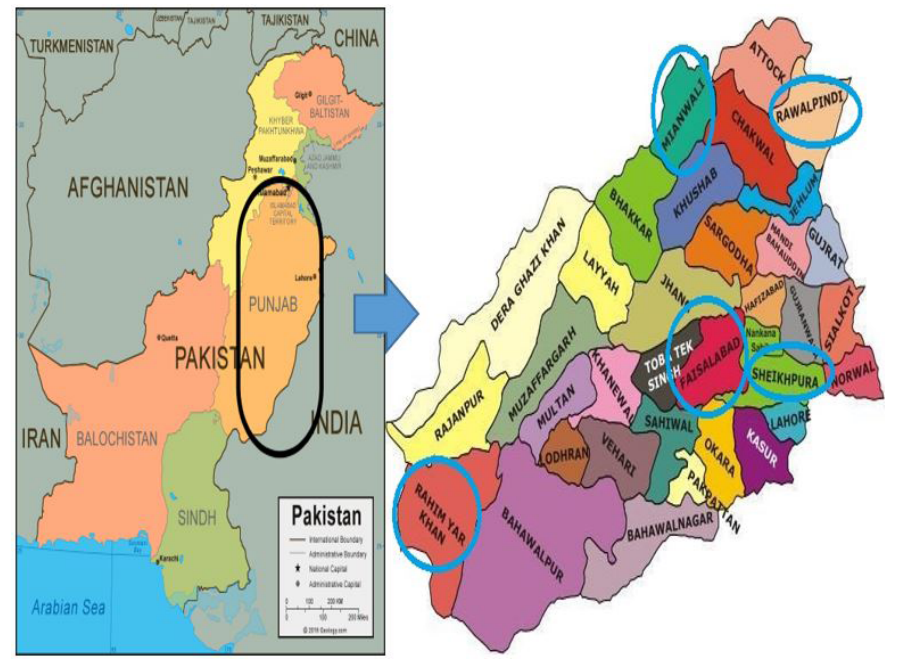

Figure 1: Targeted research areas.

\section{Results and Discussion}

Food is a fundamental necessity and an essential part of household expenditure. Most families having residence in urban areas invest a significant proportion of their income on foodstuff purchases. However, rural households in Pakistan do not spend much on staple foods and vegetables as they grow enough for themselves. They spend their earnings on various items, such as meat, fruits, honey and sugar, beverages, etc., to fulfil their needs and achieve a certain utility level. Different international organizations designed other indexes to calculate food security at different levels. Food consumption score (FCS) and the Household food insecurity access score (HFIAS) are two separate indexes used to estimate household food security concerning time. According to the
SDPI report, food security in Pakistan is getting worse with every passing day from the grassroots level nationwide compared to 2003. The number of food-insecure districts in Pakistan rose to 102 till 2009. These facts undoubtedly depict the situation of food security in the state. An increase in agricultural products' yield is required to control food insecurity, making the farming system less vulnerable to climate change (Headey and Ecker, 2013). To overcome the issue of hunger and malnutrition, Pakistan has linked up with the Scaling up Nutrition (SUN) movement in 2013 to overcome malnutrition (Malik, 2015).

\section{Food consumption score}

The food consumption behaviour of households depends upon multiple factors like income, family members, social norms, and values. The slight change in any of them results in a shift in consumer behaviour (Shahbaz et al., 2010). The food consumption score index consists of nine food groups. All these nine food groups include different types of food items that have different nutritional values and necessary for human growth and development. $1^{\text {st }}$ group is a staple food that contains different types of grains like wheat, maize, rice, quinoa, barley, etc. In statistical analysis mean, the standard deviation was calculated. A low value of the standard deviation shows that the data are close to the mean value. In contrast, a high value of standard deviation present that the numbers have more variability.

Table 1: Consumption of 9 food groups during the last seven days.

$\begin{array}{lllll}\text { Food Groups } & \text { Mean } & \text { Std. Dev. } & \text { Min } & \text { Max } \\ \text { Staple Food } & 13.26506 & 2.291403 & 0 & 14 \\ \text { Pulses } & 6.560241 & 4.080179 & 0 & 21 \\ \text { Vegetables } & 4.379518 & 1.678907 & 0 & 7 \\ \text { Fruits } & 1.361446 & 1.88505 & 0 & 7 \\ \text { Meat } & 4.506024 & 7.540394 & 0 & 28 \\ \text { Milk } & 11.87952 & 12.68299 & 0 & 28 \\ \text { Sugar } & 3.024096 & 1.06715 & 0 & 3.5 \\ \text { Oil } & 3.406627 & 0.5493948 & 0 & 3.5 \\ \text { Spices } & 0 & 0 & 0 & 0\end{array}$

Among all the nine food groups, Oil has a minimum standard deviation value, which shows that all the variables in this group benefit around the mean of all the variables. Likewise, staple food, pulses, vegetables, fruits, and sugar have lower standard deviation values, which show that all these groups have a lower degree 
of variability. The lower degree of variability means that data sets have more similar deals. On the other hand, meat and milk have a much greater higher value of variability with standard deviation values 7.540394 and 12.68299 , respectively. These results depict that food consumption behaviour depends on family members, income, and food prices. Food insecurity experts claimed that the only solution behind the execution of consumption related plans is dietary change. This is one of the most critical and essential aspects and depends upon the household head's attitude is shifting to cheap food items (Ahmed et al., 2015; Lorenzo et al., 2015). In this way, the ideal food groups essential for body growth and development are compromised and altered (Oldewage-Theron et al., 2006; Haq and Cranfield, 2011). Another researcher suggested that financial/ cooking skills and food donations could be a great solution to this regard (Hamelin et al., 2008).

\section{Household food insecurity access score (HFLAS)}

HFIAS is an index used to access household food intake for 30 days of a month and then analyzes whether the household is food deficient, at the borderline, or food secure. This index consists of 9 conditions, and then these nine conditions are divided into three categories, often, sometimes, frequently. Out of these nine conditions, seven states show a low degree of variability, which shows that data do not have much variability. Most of the households in villages have a similar pattern of food consumption. Simultaneously, two conditions show a little higher degree of variability. Those conditions are the inability to eat fewer favourite foods, eating a smaller meal than needed, and a standard deviation of 1.079481 and 1.016063 , respectively. In comparison, the standard deviation value of all other indicators is round about 0.8-0.9 approx.

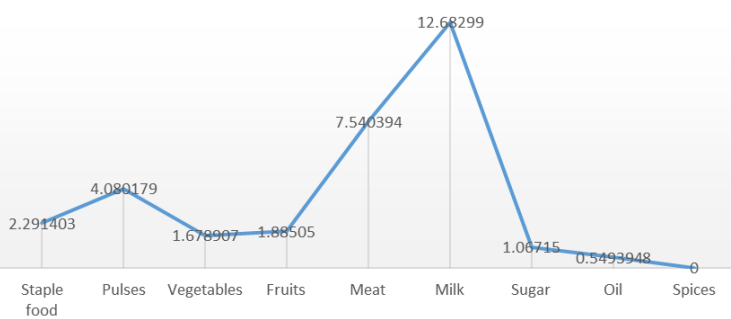

Figure 2: Graphical presentation of Standard deviation of nine food groups.

After calculating these indicators, we calculate the Food consumption score and the household food insecurity access score (HFIAS). According to these indexes, households are divided into three categories, less food consumption, borderline consumption and Acceptable consumption. The results show that according to the food consumption score every week, $34.34 \%$ of homes are at borderline. Those households consume desired nutrition, but not enough, and a slight imbalance can easily drag them into less food consumption households. Up to $65 \%$ of households in rural areas can have up to mark nutrients and food and during one week, not a single-family faces food security or food deficiency. At the same time, the value of standard deviation depicting a low degree of variability. This clearly shows households food security situations in our study area is not much different from each other.

Contrary to the abovementioned facts and figures of the FCS situation is entirely different when we consider household food security every month. Weekly, not a single household was suffering from food insecurity, but monthly $9.05 \%$ of homes are food insecure; a vast majority of 50 percent of households are at borderline. These results depict that half of the rural population is at risk. Slight fluctuation in the economy or

Table 2: Consumption behaviour of household during the last 30 days.

\begin{tabular}{|c|c|c|c|c|c|}
\hline Conditions and Frequencies of HFIAS & Obs & Mean & Std. Dev. & Min & $\operatorname{Max}$ \\
\hline \multicolumn{6}{|l|}{ Eating the kinds of less preferred foods; } \\
\hline worrying about food adequacy; & 166 & 0.560241 & 0.8488766 & 0 & 3 \\
\hline eating limited variety; & 166 & 0.8493976 & 0.9885249 & 0 & 3 \\
\hline inability to eat less favorite foods; & 166 & 0.9337349 & 1.079481 & 0 & 3 \\
\hline eating a smaller meal than needed; & 166 & 0.873494 & 1.016063 & 0 & 3 \\
\hline eating fewer meals in a day; & 166 & 0.5060241 & 0.8994745 & 0 & 3 \\
\hline failing to get food of any kind; & 166 & 0.4036145 & 0.8597316 & 0 & 3 \\
\hline sleeping at night hungry; & 166 & 0.3915663 & 0.8928952 & 0 & 3 \\
\hline going without eating anything during 24 hours a day & 166 & 0.3915663 & 0.9063687 & 0 & 3 \\
\hline
\end{tabular}

September 2021 | Volume 37 | Issue 3 | Page 758 
Table 3: Food consumption index scores of rural households.

$\begin{array}{lllllll}\text { Variable } & \begin{array}{l}\text { Observa- } \\ \text { tion }\end{array} & \text { Mean } & \text { Std. Dev. } & \begin{array}{l}\text { Less food consumption } \\ \text { household }\end{array} & \begin{array}{l}\text { Borderline } \\ \text { consumption }\end{array} & \begin{array}{l}\text { Acceptable food } \\ \text { consumption }\end{array} \\ \text { FCS } & 166 & 48.38253 & 19.1369 & 0 & 34.34 & 65.66 \\ \text { HFIAS } & 166 & 4.909639 & 5.820364 & 9.05 & 50 & 41.56\end{array}$

any other natural factor can drop them into the heap of food-insecure people. 41.56 percent of the population has resources to manage acceptable food consumption. Pakistan is also an underdeveloped country. So the findings of (ODI, 2008) can be generalized for such underdeveloped countries. Two different studies proposed an economic substitutions strategy, like shifting from luxurious food to pocket-friendly food items (Najam and Bari, 2017). Simultaneously, people can go for daily wages employment to increase monthly income (Amir et al., 2013; Naz et al., 2014), and all family members should work to uplift livelihood. Households with more family members and low income allocate a significant percentage of their financial plan to the foodstuff (Babu and Tashmatov, 1999; Babu and Pinstrup-Andersen, 2000; Bashir et al., 2012b). Household prosperity is vilest affected when the family spent a considerable amount of their earnings on the purchase of staple food (Zezza et al., 2009). The economic shock also changed household food security (Mjonono et al., 2009).

\section{Conclusions and Recommendations}

Economic issues affect food security as fluctuation in prices can trigger food insecurity and affect food security as fluctuation in prices can trigger food insecurity and affect food security. The change in prices can trigger food insecurity, especially in developing countries. There are multiple surviving approaches recommended in this context. An increase in income of people is considered an immediate solution to food security. As income drops, people prefer to eat lowpriced food or food items that are self-grown without thinking about the human body's dietary needs; thus, access and availability to sufficient, nutritious, and safe food are supposed to be complicated. However, weekly, people are less food insecure as compared to monthly basis. It is just because most people earn their livelihood daily. The chances of fluctuation in daily income are much more significant than monthly fixed income. Fluctuation in income directly affects household food consumption. The government should design such projects to help rural people maintain their earning source to uplift their living.

\section{Acknowledgements}

This study was supported by National Key R\&D Program of China (Number: 2017YFE0104600) and CAAS Science and Technology Innovation project (number; CAAS-ASTIP-2020), instituted by the Key Laboratory of Digital Agricultural Early-Warning Technology, Ministry of Agriculture, Beijing, China.

\section{Novelty Statement}

Food insecurity is one of the major issues in rural areas of many of the developing countries like Pakistan. The current research study was designed to analyze the Food Security situation in rural areas of selected districts of the Punjab, Pakistan at household level by calculating different food security measures.

\section{Author's Contribution}

Mahwish Munawar: Principal author of the paper and conducted the research.

Xu Shiwei: Supervised the research and finalized the manuscript.

Yu Wen: Data analysis and helped in preparing research instrument.

Muhammad Luqman: Prepared initial draft of manu-script.

\section{Conflict of interest}

The authors have declared no conflict of interest.

\section{References}

Ahmad, N., M. Sheikh and K. Saeed. 2015. Rural urban food consumption analysis in Pakistan: Expenditure elasticities approach. Pak. J. Commerce Soc. Sci. (PJCSS).

Ahmed, U.I., Y. Liu, M.K. Bashir and L. Ying. 2015. Food insecurity and coping strategies by micro growers in Punjab, Pakistan. J. Environ. Agric. Sci., 3: 2313-8629.

Akram, W. and M. Sial. 2019. Food security paper. Sarhad J. Agric., 35(1): 87-101. 
Alinovi, L., M. D'Errico, E. Mane and D. Romano. 2010. Livelihoods strategies and household resilience to food insecurity: An empirical analysis to Kenya. Promoting Resilience through Social Protection in Sub-Saharan Africa, pp. 28-30.

Amaral, G., J. Bushee, U.G. Cordani, A.K. Kawashita,J.H.Reynolds, F.F.M.D.E. Almeida, F.F.M. de Almeida, Y. Hasui, B.B. de Brito Neves, R.A. Fuck, Z. Oldenzaal, A. Guida, J.S. Tchalenko, D.C.P. Peacock, D.J. Sanderson, A. Rotevatn, C.W. Nixon, A. Rotevatn, D.J. Sanderson and M.C.B. Junho. 2013. Summary for policymakers. Intergovernmental Panel on Climate Change (Ed.). Clim. Change 2013 Phys. Sci. Basis, Cambridge University Press. 369(1): 1-30.

Amir, R.M., B. Shahbaz, T. Ali and M.I. Zafar. 2013. Analysis of household food security concerns and coping strategies of small farmers in northwestern highlands of Pakistan. Pak. J. Agric. Sci., 50(3): 505-510.

Anila, S., 2011. Determinants of food security at household level in Pakistan. Afr.J.Bus. Manage., 5(34):109-116. https://doi.org/10.5897/ AJBM11.1441

Arene,C.J.and M.R.C.Anyaeji.2010.Determinants of food security among households in nsukka metropolis of Enugu State, Nigeria. Pak. J. Soc. Sci., 30(1): 9-16.

Arshad, S. and A. Shafqat. 2012. Food security indicators, distribution and techniques for agriculture sustainability in Pakistan. Int. J. Appl. Sci. Technol., 2(5): 137-147.

Asghar, Z. and A. Muhammad. 2013. Munich personal repec archive socio-economic determinants of household food insecurity in Pakistan socio-economic determinants of household food insecurity in pakistan. pp. 21510.

Aslam, M., 2016. Agricultural productivity current scenario, constraints and future prospects in Pakistan. Sarhad J. Agric., 32(4): 289-303. https://doi.org/10.17582/journal. sja/2016.32.4.289.303

Babu, S.C. and A. Tashmatov. 1999. Attaining food security in Central Asia-Emerging issues and challenges for policy research. Food Policy. https://doi.org/10.1016/S03069192(99)00052-4

Babu, S. and P.Pinstrup-Andersen.2000.Achieving food security in Central Asia. Current challenges and policy research needs. Food Policy. https:// doi.org/10.1016/S0306-9192(00)00031-2

Bashir, M.K., S. Schilizzi and R. Pandit. 2012a. Are the determinants of food insecurity for landless households different from that of other rural households? Pak. J. Agric. Sci., 49(3): 363-370.

Bashir, M.K., S. Schilizzi and R. Pandit. 2012b. The determinants of rural household food security for landless households of the Punjab, Pakistan. Working Papers.

Bashir, M.K., S. Schilizzi and R. Pandit. 2012c. The determinants of rural household food security in the Punjab, Pakistan: An econometric analysis. Working Papers.

Bogale, A., 2012. Vulnerability of smallholder rural households to food insecurity in Eastern Ethiopia. Food Security. https://doi. org/10.1007/s12571-012-0208-x

Coates, J., A. Swindale and P. Bilinsky. 2007. Household Food Insecurity Access Scale (HFIAS) for measurement of food access: Indicator guide. Washington, DC: Food and Nutrition Technical. https://doi.org/10.1037/ e576842013-001

Coelho, A.B., D.R.D. Aguiar and J.S. Eales. 2010. Food demand in Brazil: an application of Shonkwiler andamp; Yen Two-Step estimation method. Estudos Econ. (São Paulo), 40(1): 186-211. https://doi.org/10.1590/S010141612010000100007

Deitchler, M., T. Ballard, A. Swindale and J. Coates. 2011. Introducing a simple measure of household hunger for cross-cultural use. Washington, DC: Food and Nutrition.

Dercon, S. and P. Krishnan. 1996. Income portfolios in rural Ethiopia and Tanzania: Choices and constraints. J. Dev. Stud., 32(6): 850-875. https://doi.org/10.1080/00220389608422443

Economist Intelligence Unit. 2019. Global food security index 2019: Strengthening food systems and the environment through innovation and investment. Economist Intell. Unit Limited 2019, 1-48. http://digitalcommons.uconn.edu/ econ_wpapers/199605\%0A; http://www.rspo. org/file/GHGWG2/4_oil_palm_and_land_ use_change_Gunarso_et_al.pdf\%0Ahttp:// www.plaas.org.za/sites/default/files/ publications-pdf/PLAAS Rural Report Book 1 - Stephen - Web.pdf\%0Ahttp://eb

FAO, 2012. The state of food insecurity in the 
world 2012. In: FAO.

Farkhanda,A.,F.Nazir,A.A.Maann and S.Tasleem. 2009. Household food security situation in slum areas of Faisalabad.Pak.J.Agric. Sci., 46(2):148152. https://auth.lib.unc.edu/ezproxy_auth. php?url=http://search.ebscohost.com/login.asp $\mathrm{x}$ ?direct=trueanddb=1hhandAN=20093272964 andsite $=$ ehost-liveandscope $=$ site; $\% 5 \mathrm{Cnhttp}: / /$ www.cabi.org/cabdirect/showpdf. aspx?PAN=20093272964;\%5Cnhttp://www. pak-jas.com

Felker-Kantor, E. and C.H. Wood. 2012. Femaleheaded households and food insecurity in Brazil. Food Security. https://doi.org/10.1007/ s12571-012-0215-y

Grebmer, K., J. von, Bernstein, N. Prasai, S. Yin and Y. Yohannes. 2015. Global hunger index: Armed conflict and the challenge of hunger. Int. Food Policy Inst.,

Habib, M.A., C. Raynes-Greenow, S.B. Soofi, N. Ali, S. Nausheen, I. Ahmed, Z.A. Bhutta and K.I. Black. 2018. Prevalence and determinants of iron deficiency anemia among non-pregnant women of reproductive age in Pakistan. Asia Pac. J. Clin. Nutr., 27(1): 195-203.

Hamelin, A.M., C. Mercier and A. Bédard. 2008. Perception of needs and responses in food security: Divergence between households and stakeholders. Public Health Nutrition. https:// doi.org/10.1017/S1368980008003406

Haq, Z., and J. Cranfield. 2011. Household food demand in Pakistan: Does demand specification matter? Afr. J. Bus. Manage., https://doi. org/10.5897/AJBM11.461

Headey, D. and O. Ecker. 2013. Rethinking the measurement of food security: From first principles to best practice. Food Security, 5(3): 327-343. https://doi.org/10.1007/s12571-0130253-0

Hussain, Z. and W. Akram. 2008. Persistent food insecurity from policy failures in Pakistan. Pak. Dev. Rev., https://doi.org/10.30541/ v47i4IIpp.817-834

Kassie, M., S.W. Ndiritu and J. Stage. 2014. What determines gender inequality in household food security in Kenya? Application of exogenous switching treatment regression. World Dev., https://doi.org/10.1016/j. worlddev.2013.10.025

Khan, R.E.A., T. Azid and M.U. Toseef. 2012. Determinants of food security in rural areas of
Pakistan. Int. J. Soc. Econ., 39(12): 951-964.

Lorenzo, T., E. Van Pletzen and M. Booyens. 2015.

Determining the competences of community based workers for disability-inclusive development in rural areas of South Africa, Botswana and Malawi. Rural and Remote Health. https://doi.org/10.22605/RRH2919

Løvendal, C.R., M. Knowles and N. Horii. 2004. Understanding vulnerability to food insecurity lessons from vulnerable livelihood profiling ESA Working Paper No. 04-18. Understanding Vulnerability to Food insecurity Lessons from Vulnerable Group Profiling. 04,1-26. www.fao. org/es/esa

Malik, M., 2015. Pakistan economic survey 201516. In: Pakistan Economic Survey.

Mango,N.,B.Zamasiya, C.Makate, K. Nyikahadzoi and S. Siziba. 2014. Factors influencing household food security among smallholder farmers in the Mudzi district of Zimbabwe. Development Southern Africa. https://doi.org /10.1080/0376835X.2014.911694

Maxwell, S., 1996. Food security: A post-modern perspective. Food Policy, 21(2): 155-170. https://doi.org/10.1016/0306-9192(95)000747

Maziya, M., M. Mudhara and J. Chitja. 2017. What factors determine household food security among smallholder farmers? Insights from Msinga, KwaZulu-Natal, South Africa. Agrekon, 56(1): 40-52. https://doi.org/10.108 $0 / 03031853.2017 .1283240$

Mebratu, N.F., 2018. Determinants of food insecurity among rural households of South Western Ethiopia. J. Dev. Agric. Econ., 10(12): 404-412. https://doi.org/10.5897/ JDAE2018.0999

Mjonono, M., M. Ngidi and S.L. Hendriks. 2009. Investigating household food insecurity coping strategies and the impact of crop production on food security using coping strategy index (csi). Fram Manage.,

Morton, L.W., E.A. Bitto, M.J. Oakland and M. Sand. 2007. Accessing food resources: Rural and urban patterns of giving and getting food. Agric. Hum. Values, 25(1): 107-119. https:// doi.org/10.1007/s10460-007-9095-8

Muhoyi, E., T.J. Mukura, D. Ndedzu, T. Makova and O. Munamati. 2014. Determinants of household food security in Murehwa District, Zimbabwe. J. Econ. Sustain. Dev., Www.Iiste. 


\section{Org ISSN}

Najam, A. and F. Bari. 2017. Pakistan human development index report. In: Pakistan human development index report.

Naz, M., I.A. Khan and B. Shahbaz. 2014. Role of rural women in agriculture and household food security in Faisalabad district. Pak. J. Agric. Sci., 51(3): 757-761.

Nyikahadzoi, K., S. Siziba, N. Mango, P. Mapfumo, A. Adekunhle and O. Fatunbi. 2012. Creating food self reliance among the smallholder farmers of eastern Zimbabwe: Exploring the role of integrated agricultural research for development. Food Security. https://doi. org/10.1007/s12571-012-0218-8

ODI, 2008. Rising food prices: A global crisis. World.

Oldewage-Theron, W.H., E.G. Dicks and C.E. Napier. 2006. Poverty, household food insecurity and nutrition: Coping strategies in an informal settlement in the Vaal Triangle, South Africa. Public Health. https://doi.org/10.1016/j. puhe.2006.02.009

Owusu,V.,A.Abdulai and S.Abdul-Rahman.2011. Non-farm work and food security among farm households in Northern Ghana. Food Policy. https://doi.org/10.1016/j.foodpol.2010.09.002

Oyekale, T.O., A.O. Ayegbokiki and T.Y. Adebayo. 2017. Analysis of Rural Households and \#8217; Food security status in Ogun State, Nigeria. J. Agribus. Rural Dev., 16(1): 163-174. https:// doi.org/10.17306/J.JARD.2017.00326

Rose,D.D.,2008.Interventions to reduce household food insecurity: A synthesis of current concepts and approaches for Latin America. Revista de Nutrição, 21(suppl): 159s-173s. https://doi. org/10.1590/S1415-52732008000700014

Shahbaz, B., T. Ali, I.A. Khan and M. Ahmad. 2010. An analysis of the problems faced by farmers in the mountains of northwest Pakistan: Challenges for agri extension. Pak. J. Agric. Sci.,
47(4), 417-420.

Sheikh, S., R. Iqbal, R. Qureshi, I. Azam and R. Barolia. 2020. Adolescent food insecurity in rural Sindh, Pakistan: A cross-sectional survey. BMC Nutr., 6(1): 1-9. https://doi.org/10.1186/ s40795-020-00343-w

Sultana, H., N. Ali, M.M. Iqbal and A.M. Khan. 2009. Vulnerability and adaptability of wheat production in different climatic zones of Pakistan under climate change scenarios. Climatic Change, https://doi.org/10.1007/ s10584-009-9559-5

United Nations Development Programme (UNDP), 2020. Human development report 2020. The next frontier Human development and the Anthropocene Human Development Report 2020. http://hdr.undp.org

USAID, 2010. Stape foods value chain analysis country report, Kenya. In USAID Report.

Vaitla, B., J. Coates and D. Maxwell. 2015. Comparing household food consumption indicators to inform acute food insecurity phase classification. Food and nutrition technical assistance III Project (FANTA). FHI 360/Food and Nutrition Technical Assistance III Project (FANTA), December, 165.

von Grebmer, K., A. Saltzman, E. Birol, D. Wiesmann, N. Prasai,S. Yin, Y. Yohannes, P. Menon, J. Thompson and A. Sonntag. 2014. The challenge of hidden hunger. Global Hunger Index.

World Food Programme, 2009. Emergency Food Security Assessment Handbook second edition. pp. 68-70. www.wfp.org

Zezza, A., B. Davis, C. Azzarri, K. Covarrubias, L. Tasciotti and G. Anriquez. 2009. The impact of rising food prices on the poor. Contributed paper prepared for presentation at the international association of agricultural economists conference, Beijing, China, August 16-22, 2009. 